\title{
Techno-economic assessment of collagen casings waste management
}

\author{
J. Maroušek ${ }^{1}$ A. Maroušková ${ }^{1}$ K. Myšková ${ }^{2}$ J. Váchal $^{1} \cdot$ M. Vochozka ${ }^{1} \cdot$ \\ J. Žák ${ }^{1}$
}

Received: 13 November 2014/Revised: 7 April 2015/Accepted: 29 June 2015/Published online: 22 July 2015

(C) Islamic Azad University (IAU) 2015

\begin{abstract}
Regarding the price of meat product filling in comparison with the negligible cost of the collagen casings, whole roll of the casings is discharged only on suspicion of a small cut during handling. Once the casings are designed to be biologically resistant, they represent relatively problematic waste that is nowadays rather transported to landfills. This represents a significant cost; once the role is opened, it becomes extremely voluminous. The long-term study that was carried out on a commercial scale assessed two methods of utilization: composting of highly disintegrated casings and composting of charred casings. Robust qualitative and financial analysis revealed that the composting of charred casings was more meaningful both from agrochemical and financial point of view.
\end{abstract}

Keywords Collagen waste $\cdot$ Composting $\cdot$ Wildlife pass · Biochar · Financial assessment

\section{Introduction}

Collagen is an abundant protein constituent of connective tissue in vertebrate and invertebrate animals (Aristippos 2002; Gómez-Guillén et al. 2011; Jayathilakan et al. 2011). Similar to cellulose in plants, collagen molecules support mechanical stresses transferred to them by a lowmodulus matrix. The properties of collagen were

J. Maroušek

josef.marousek@gmail.com

1 Institute of Technology and Businesses in České Budějovice, Okružní 517/10, Ceske Budejovice 370 01, Czech Republic

2 University in Brno, Zemědělská 1, Brno 613 00, Czech Republic repeatedly reviewed recently (Maynes 2012; Harper et al. 2012) as they are of a great interest especially to food science (gels and edible films). Edible coatings can improve the quality of fresh, frozen, and processed meat, poultry, and seafood products by retarding moisture loss, reducing lipid oxidation and discoloration, enhancing product appearance in retail packages by eliminating dripping, sealing in volatile flavors, functioning as carriers of food additives such as antimicrobial and antioxidant agents, and reducing oil uptake by battered and breaded products during frying (Khan et al. 2013). Thermal or chemical dissociation of collagen polypeptide chain forms products known as gelatin. Insoluble collagen is converted to soluble gelatin by acid or alkaline processing. Two processes are mainly used for the commercial production of gelatin. In the first process, the collagen in hide or demineralized bone is partly depolymerized by prolonged liming that breaks down covalent cross-links. The occurring hydrolysis results in extensive release of collagenous material, which is solubilized at near-neutral $\mathrm{pH}$ at temperatures of $60-90{ }^{\circ} \mathrm{C}$ (type B gelatin). The acid process (type B gelatin) involves soaking skin or bone in a dilute acid followed by extraction at acid $\mathrm{pH}$. This represents less expensive and technologically advanced variant, the edible collagen casings are dominating the "cooked" and "dry" sausage production all over the world. Koolmees et al. (2004) estimated the world trade of casings to be USD 2.5 billion annually. Regardless of the latest development on the layer uniformity, flexibility under various processing conditions and strength, situations often occur in operation, where the regenerated collagen casings tear during handling or attaching onto the stuffing equipment. As reviewed, the casings are extremely lightweight; therefore, the main costs are not linked to the loss of the material, but its waste management. The landfilling, which is currently 
practiced, does not seem suitable from the environmental point of view because the volume of landfills increases worldwide disproportionately (Morris and Barlaz 2011). In addition, small producers of traditional sausage products may encounter technical and financial difficulties to comply with official food safety regulations (LatorreMoratalla et al. 2010).

The motivation was to assess the possibility of reducing the cost linked with the waste management of the collagen casings both from environmental and financial point of view. Two hypotheses were tested: firstly to assess the composting of the collagen casing in the deeply disintegrated form and secondly to assess the incorporation into compost after turning it into biochar. Both products could be used as soil improvers in construction of the wildlife passes across motorways in order to achieve fast and allseason vegetation cover.

\section{Materials and Methods}

\section{Material}

Edible collagen casings suited for the manufacture of cooked sausages (e.g., "Weiner," "Frankfurter," or "Bradwurst" type), and dry sausages with open ends, code Red 11, were obtained from local producer (Viscofan s.r.o., Czech Republic). According to the product data sheet provided, the composition was as follows: collagen 47-52 \%; water 22-22.5\%; humectant $16-17 \%$; cellulose $5 \%$; ash $\left(550{ }^{\circ} \mathrm{C}\right) 1-3.5 \%$; vegetable oil $3.5-5 \%$; color components (E 120; E 127; E 129; and E 160b) 0-3\%. Caliber $22.5 \mathrm{~mm}$; stuffing caliber $22.5 \pm 0.5 \mathrm{~mm}$; maximum diameter of stuffing horn $12.5 \mathrm{~mm}, \mathrm{pH}$ 5.6-6.2. The collagen casings were packed in cardboard caddies to preserve the product against any kind of deterioration or contamination. Cardboard caddies were wrapped into plastic foil impermeable to $\mathrm{O}_{2}$ and $\mathrm{H}_{2} \mathrm{O}$. The producer declared that the collagen casings are packed into modified atmosphere of $70 \% \mathrm{~N}_{2}$ and $30 \% \mathrm{CO}_{2}$. At any time, the casings were stored in temperatures lower than $20^{\circ} \mathrm{C}$.

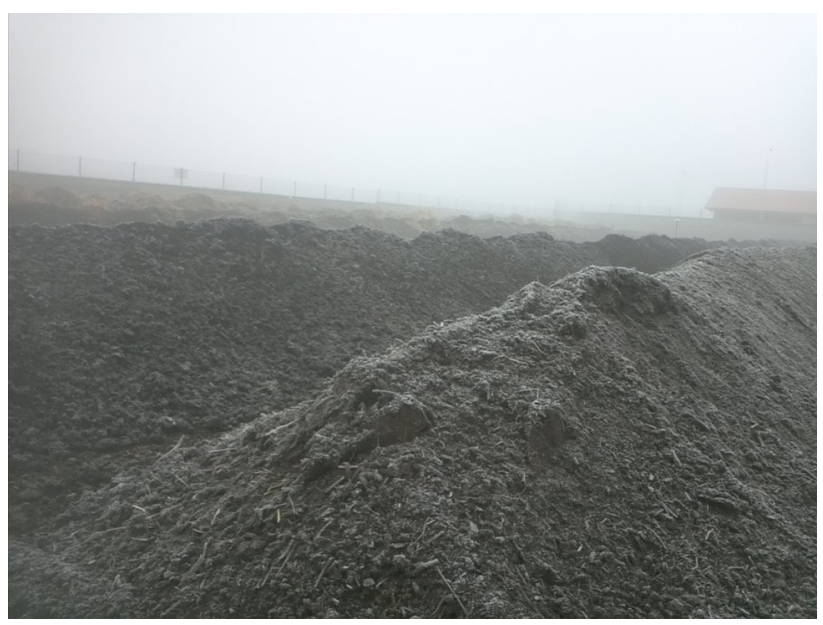

Fig. 1 Utilization of the collagen casings was carried out for 1 year in a commercial scale $\left(11: 000 \mathrm{t}^{\text {year }}{ }^{-1}\right)$, windrow composting on paved surface (height of the line $1.6 \mathrm{~m}$ )

\section{Method A}

Prior to the deep disintegration by steam explosion, the collagen casings had to be macerated to enable its further manipulation. The M2 continuous macerator (BiomassTechnology a.s., Czech Republic) that operated at $100 \mathrm{~kg} \mathrm{~h}^{-1}, 85^{\circ} \mathrm{C}$, and hydraulic retention time $200 \mathrm{~s}$ (as traceable in Maroušek 2013) was used to carry out this pretreatment step. The voluminous and lightweight collagen casings were turned into a mash of $10 \%$ volatile solids (VS). The reason for using this type of macerator is that it enables the underwater maceration which is advantageous to deaerate the material. If the casings were not deaerated, it would very likely result in a low performance (pressure fluctuations in the high-pressure reactor and leakage through the expansion tourniquet) of the subsequent steam explosion technology. As mentioned, the hot underwater macerated collagen casings were delivered by the highpressure screw pump into the continuous TTP5 steam explosion technology (BiomassTechnology a.s.) operating at $100 \mathrm{~kg} \mathrm{~h}^{-1}, 0.8 \mathrm{MPa}$, tourniquet explosions of $0.3 \mathrm{~L}$ in $0.1 \mathrm{~s}$, and hydraulic retention time $14 \mathrm{~min}$ as traceable in 
Maroušek et al. (2012). The watery mash obtained was decanted, and the residue obtained passed the double screw dewatering press (PHARMIX, s.r.o, Czech Republic) that operated at 15 revolutions per minute, in order to achieve the backpressure spring tension of $350 \mathrm{~N}$. This setup resulted in dewatering the mash to roughly $60 \% \mathrm{VS}$. The deeply disintegrated collagen casings were mixed (1:9, by VS) with the organic material (grass clippings, leaves, various wastes from agricultural production, organic waste from catering facilities, and households) entering the commercial scale (Fig. 1) of composting plant (KOBRA Údlice, s.r.o., Czech Republic). The composting was carried out for 1 year operating according to COMPO technology (Compost Systems, GmbH, Austria).

\section{Method B}

The collagen casings were macerated at the same conditions as stated in the previous chapter, however, without the presence of water. The dust obtained from the casings was subjected to the S-1 horizontal pyrolysis unit (AIVOTEC, s.r.o., Czech Republic), which is run by the waste heat from the JSM 312 methane combustion engine (GE Jenbacher BmbH, Germany) as traceable in Maroušek (2013). The operating conditions were as follows: $400{ }^{\circ} \mathrm{C}$, 20 -min retention time, and $800 \mathrm{~kg} \mathrm{VS} \mathrm{h}^{-1}$. The biochar obtained (Fig. 1) was mixed (1:9, by VS) with the organic material and also composted for 1 year as described in previous section ("Method A").

\section{Analytical methods}

Qualitative analyses were carried out externally (AGROLA, spol. s r.o., Czech Republic) according to actual EU legislative (ČSN 46 5735). The NOVA 4200e surface analyzer (Quantachrome Instruments, Florida, USA) was used to analyze the microporosity. Gas chromatography and mass spectrometry analyses on polycyclic aromatic hydrocarbons (PAHs), dioxins, furans, Salmonella sp., thermo-tolerant bacteria, Enterococcus as well as element analyses and analyses on heavy metals were done externally (AIVOTEC s.r.o., Czech Republic) according to the

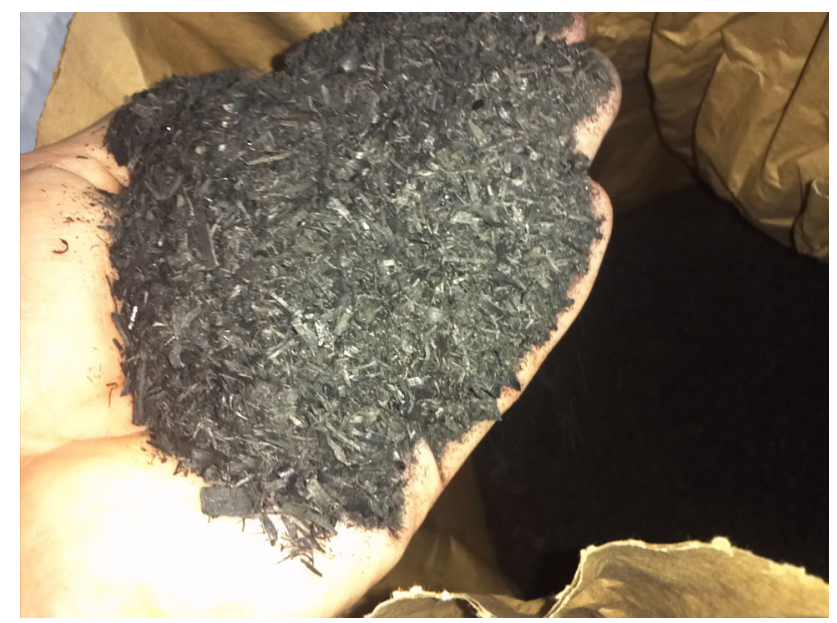

Fig. 2 Collagen casing subjected to maceration $\left(100 \mathrm{~kg} \mathrm{~h}^{-1}, 85^{\circ} \mathrm{C}\right.$, and hydraulic retention time $200 \mathrm{~s})$ followed by pyrolysis $\left(400{ }^{\circ} \mathrm{C}\right.$, 20 -min retention time, and $800 \mathrm{~kg} \mathrm{VS} \mathrm{h}^{-1}$ )

EU legislative and standard laboratory procedures. Other routine analytical methods were performed (where appropriate $n=6 ; \alpha=0.05$ ) as traceable in previous publications of authors referred above. The financial analyses are based on the net cash flow.

\section{Results and Discussion}

Routine laboratory analysis confirmed that the quality of the collagen casings is in a good agreement with the product data sheet obtained from the local manufacturer. Not surprisingly, the external analysis on PAHs, dioxins, furans, and heavy metals confirmed that the collagen casings are deep under the limits of EU legislative for composts (ČSN 46 5735) and should not be a source of inhibition of microbial life and phytotoxicity, respectively. The collagen casings with the brightest red color were chosen for the assessment on purpose; however, no residues (Method A) were observable after 1 year of composting (Fig. 2). We expect this is a consequence of the deep disintegration carried out by the underwater maceration followed by the steam explosion. The surface analyzer revealed that the 
Table 1 Analyses of composts

\begin{tabular}{lllllrr}
\hline & A & B & C & D & E & F \\
\hline Ultra-KOB-1 & $50.2 \pm 1.1$ & $45.8 \pm 0.7$ & $2.4 \pm 0.3$ & $6.4 \pm 0.1$ & $6.803 \pm 0.047$ & $14.92 \pm 0.56$ \\
Addition of collagen & $51.4 \pm 1.2$ & $46.0 \pm 1.3$ & $2.3 \pm 0.4$ & $6.4 \pm 0.2$ & $6.861 \pm 0.093$ & $14.09 \pm 0.70$ \\
Addition of biochar & $44.4 \pm 1.1$ & $45.8 \pm 0.9$ & $2.1 \pm 0.2$ & $7.7 \pm 0.1$ & $4.537 \pm 0.059$ & $523.44 \pm 14.36$ \\
\hline
\end{tabular}

A, Humidity (\%); B, combustible substances (\% VS); C, $\mathrm{N}_{\text {TOT }}(\% \mathrm{VS}) ; \mathrm{D}, \mathrm{pH}$; E, density $\left(\mathrm{kg} \mathrm{L}^{-1}\right)$; F, cation-exchange capacity (cmol ${ }^{+} \mathrm{kg}^{-1}$ ), $n=6 ; \alpha=0.05$

microporosity increased during the disintegration as follows: BET surface area $+9 \%$; single-point surface area $(\mathrm{P} /$ $\mathrm{Po}=0.2)+7 \%$; Langmuir surface area $+3 \%$; micropore area $+1 \%$; and external surface area $+19 \%\left(\right.$ all $\left.\mathrm{m}^{2} \mathrm{~g}^{-1}\right)$. We believe that this deep disintegration step broke the upper surface layers of the casings (tailored to prolong the shelf life), which resulted into significant increase on the biodegradability of the organic carbon. If we compare the composting Method A with a blank sample (Ultra-KOB-1) by the qualitative indicators required by EU standards (Table 1), we can state that there is almost no difference from technological point of view. However, the financial point of view is questionable. While the production cost of Ultra-KOB-1 is 13.3 EUR t $^{-1}$ (VS), the production cost of compost produced under Method A (deep disintegration) increased up to 17.5 EUR t $^{-1}$. Notwithstanding the advanced energy recovery, which is obtained by the TTP5 steam explosion technology, detailed view of the costs shows that the increase was caused notably by the consumed electricity and amortization of the technology. Despite this, however, it was proved that the Method A is reasonable because according to current prices, the composting of $1 \mathrm{t}$ of the collagen waste saves 13.5 EUR per landfilling and three additional EUR per transport. From another perspective, this means that the production cost was reduced to 1 EUR t $^{-1}$ !

Analysis on the microporosity (BET surface area +504\%; single-point surface area $(\mathrm{P} / \mathrm{Po}=0.2)+99 \%$; Langmuir surface area $+30 \%$; micropore area $+1607 \%$; external surface area $+2980 \%$, all $\mathrm{m}^{2} \mathrm{~g}^{-1}$ ) and elemental analysis ( $\mathrm{C}: 81.5 \% ; \mathrm{H}_{2}: 3.0 \% ; \mathrm{O}_{2}: 0.6 \% ; \mathrm{N}_{2}: 2.9 \%$; ashes: $9.1 \%$, all VS) of the biochar obtained by Method $\mathrm{B}$, following the degradation of organic matter, indicated that the compost should have completely different qualitative indicators. Table 1 shows that expectations were justified. Firstly, the humidity is roughly $6 \%$ lower, which seems to be linked to the fall of density by onethird. According to the literature reviewed by Lehmann et al. (2011), the biochar application can also change soil bulk density, with possible effects on soil-water relations, rooting patterns, and soil fauna. This occurs both because the density of biochar is lower than that of some minerals, and because biochar contains macro- and micropores, which can hold air or water, greatly reducing the bulk density of the entire biochar particle. The robust review of Lehmann et al. (2011) explains also the increase on $\mathrm{pH}$ and cation-exchange capacity. Once the pyrolysis technology is based on energy recuperation, it is not surprising that the production price of the compost obtained by Method B is completely negligible or slightly negative, respectively. From both biotechnological and financial perspectives, we could say that correct methods for the utilization of the collagen casings were found! But why is the business with composts stagnating? The producers of composts often wonder why farmers do not intend to buy their composts in spite of the relatively low cost (Kolár et al. 2011). The answer is: the yield effect of fertilization with these composts is minimal, and due to a low content of nutrients, it is necessary to apply tens of $\mathrm{tha}^{-1}$, which increases transportation and handling costs. In comparison with so-called green manure, i.e., ploughing down green fresh matter of clover, lucerne, stubble catch crops, and crops designed for green manure, e.g., mustard and some rape varieties, the fertilization with these false composts does not have any advantage. If we expressed the value of our composts only by nutrients (Table 1) 
without any calculations, we can conclude that the price is negligible in comparison with the costs of application. What is real value of the compost? According to Bernal et al. (2009), compost should be of high quality in order to guarantee its marketability. But what should the real compost be like? Kolár et al. (2011) state that it is evident from the definition: The compost is a decomposed, partly humified organomineral material in which a part of its organic component is stabilized by the mineral colloid fraction. It is characterized by high ion-exchange capacity and high buffering capacity, and is resistant to fast mineralization. The crucial thing is that the compost will maintain nutrients in the soil by its ion-exchange reactions and that it will protect them against elution from topsoil and subsoil layers to bottom soil or even to groundwater, no matter whether these plant nutrients originate from the compost itself or from mineral fertilizers or from a natural source-the soilforming substrate in the soil-forming process. In this sense, strategies such as addition of a bulking agent with degradable organic $\mathrm{C}$, to enhance initial $\mathrm{N}$ immobilization, and process control (moisture, temperature, aeration/turning, and particle size) have been shown to reduce ammonia volatilizations and hence nitrogen losses, these being a major concern in manure composting from an environmental point of view (Bernal et al. 2009). The agricultural value of a compost increases when the organic matter reaches a high level of stability and maturity, which cannot be established by a single parameter.

\section{Conclusion}

It was technologically and financially validated that composting of the waste from collagen casing might serve as a good way to prevent landfilling. Deep disintegration is a necessary condition to shorten the aerobic fermentation of the collagen. If the casings are pyrolyzed into biochar, the financial and qualitative indicators of the compost may be significantly increased. However, the conventional farmers do not have interest in composts nowadays because the calculation on nutrients indicates that the application itself is already loss-making. Application of compost is a long- term investment, which many of them cannot afford under the current situation. It would be appropriate to focus more research on what the present preference of short-term profit may cause for the soil fertility in the future. At least but not last, it is financially justifiable to use both soil improvers for instance in the construction of the wildlife passes across motorways in order to achieve fast and all-season vegetation cover.

Acknowledgments The corresponding author acknowledges the financial support coupled with award of the Czech Innovation Award 2013 from Ceské inovace, o.p.s. and The Quality Innovation of the Year 2014 award from Finnish Quality Association.

\section{References}

Aristippos G (2002) Protein-based films and coatings. CRC Press, Boca Raton

Bernal MP, Alburquerque JA, Moral R (2009) Composting of animal manures and chemical criteria for compost maturity assessment: a review. Bioresour Technol 100:5444-5453

Gómez-Guillén MC, Giménez B, López-Caballero ME, Montero MP (2011) Functional and bioactive properties of collagen and gelatin from alternative sources: a review. Food Hydrocoll 25:1813-1827

Harper BA, Barbut S, Lim L-T, Marcone MF (2012) Microstructural and textural investigation of various manufactured collagen sausage casings. Food Res Int 49:494-500

Jayathilakan K, Sultana K, Radhakrishna K, Bawa AS (2011) Utilization of byproducts and waste materials from meat, poultry and fish processing industries: a review. J Food Sci Technol 49:278-293

Khan M, Adrees M, Tariq M, Sohaib M (2013) Application of edible coating for improving meat quality: a review. Pak J Food Sci 23:71-79

Kolář L, Kužel S, Peterka J, Borová-Batt J (2011) Utilisation of waste from digesters for biogas production. In: dos Santos Bernardes MA (ed) Biofuels engineering process technology. InTech, New York, pp 191-220

Koolmees PA, Tersteeg MHG, Keizer G, van den Broek J, Bradley R (2004) Comparative histological studies of mechanically versus manually processed sheep intestines used to make natural sausage casings. J Food Prot 67:2747-2755

Latorre-Moratalla ML, Bover-Cid S, Talon R, Garriga M, Zanardi E, Ianieri A et al (2010) Strategies to reduce biogenic amine accumulation in traditional sausage manufacturing. LWT-Food Sci Technol 43:20-25 
Lehmann J, Rillig M, Thies J, Masiello CA, Hockaday WC, Crowley D (2011) Biochar effects on soil biota-a review. Soil Biol Biochem 43:1812-1836

Maroušek J (2013) Pretreatment of sunflower stalks for biogas production. Clean Technol Environ 15:735-740

Maroušek J, Kondo Y, Ueno M, Kawamitsu Y (2012) Commercialscale utilization of greenhouse residues. Biotechnol Appl Biochem 60:253-258
Maynes R (2012) Structure and function of Collagen types. Elsevier, Amsterdam

Morris JWF, Barlaz MA (2011) A performance-based system for the long-term management of municipal waste landfills. Waste Manag 31:649-662 